\title{
Simulated pre-industrial climate in Bergen Climate Model (version 2): model description and large-scale circulation features
}

\author{
O. H. Otterå ${ }^{1,2}$, M. Bentsen ${ }^{1,2}$, I. Bethke ${ }^{1,2}$, and N. G. Kvamstø $\emptyset^{2,3}$ \\ ${ }^{1}$ Nansen Environmental and Remote Sensing Center, Thormøhlensgt. 47, 5006 Bergen, Norway \\ ${ }^{2}$ Bjerknes Centre for Climate Research, Allégt. 55, 5007 Bergen, Norway \\ ${ }^{3}$ Geophysical Institute, University of Bergen, Allégt. 70, 5007 Bergen, Norway \\ Received: 28 April 2009 - Published in Geosci. Model Dev. Discuss.: 14 May 2009 \\ Revised: 9 September 2009 - Accepted: 15 September 2009 - Published: 11 November 2009
}

\begin{abstract}
The Bergen Climate Model (BCM) is a fullycoupled atmosphere-ocean-sea-ice model that provides stateof-the-art computer simulations of the Earth's past, present, and future climate. Here, a pre-industrial multi-century simulation with an updated version of BCM is described and compared to observational data. The model is run without any form of flux adjustments and is stable for several centuries. The simulated climate reproduces the general largescale circulation in the atmosphere reasonably well, except for a positive bias in the high latitude sea level pressure distribution. Also, by introducing an updated turbulence scheme in the atmosphere model a persistent cold bias has been eliminated. For the ocean part, the model drifts in sea surface temperatures and salinities are considerably reduced compared to earlier versions of BCM. Improved conservation properties in the ocean model have contributed to this. Furthermore, by choosing a reference pressure at $2000 \mathrm{~m}$ and including thermobaric effects in the ocean model, a more realistic meridional overturning circulation is simulated in the Atlantic Ocean. The simulated sea-ice extent in the Northern Hemisphere is in general agreement with observational data except for summer where the extent is somewhat underestimated. In the Southern Hemisphere, large negative biases are found in the simulated sea-ice extent. This is partly related to problems with the mixed layer parametrization, causing the mixed layer in the Southern Ocean to be too deep, which in turn makes it hard to maintain a realistic sea-ice cover here. However, despite some problematic issues, the pre-industrial control simulation presented here should still be appropriate for climate change studies requiring multi-century simulations.
\end{abstract}

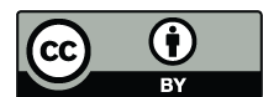

Correspondence to: O. H. Otterå (odd.ottera@bjerknes.uib.no)

\section{Introduction}

The recently published Intergovernmental Panel of Climate Change report (IPCC AR4) has raised global awareness on climate change issues considerably. Consequently, there is now a growing concern over the ongoing and possible future environmental changes depicted in the IPCC reports. The many different projections of possible future climate changes described in the IPCC reports are made possible by the use of numerical models of the earth system. The improvements in state-of-the-art climate models have increased our confidence in their ability to simulate future climate change. However, the models still show significant differences, both in terms of the simulated climate change and more fundamental aspects of the representation of internal processes and feedbacks. Although, an accurate simulation of the current climate represents an important achievement, it does not guarantee that a model will correctly simulate climatic conditions very different from that of the present, such as, for example, those due to increasing greenhouse gas concentrations. Past climates may provide useful tests for GCMs by enabling a comparison between model simulations and paleoclimatic reconstructions, and thereby providing a means of assessing their capability to simulate past changes of climate.

The original version of Bergen Climate Model (BCM) first described by Furevik et al. (2003), is a global fullycoupled atmosphere-ocean-sea-ice general circulation model that has been used for a range of climate change studies in recent years (Bentsen et al., 2004; Otterå et al., 2004; Mignot and Frankignoul, 2004; Sorteberg et al., 2005; Bethke et al., 2006; Yu et al., 2008). The main model modules in BCM are the ARPEGE-CLIMAT atmospheric general circulation model (Déqué et al., 1994) and a modified version of Miami Isopycnic Coordinate Ocean Model (MICOM, Bleck et al. 1992). In the second version of BCM (hereafter referred

Published by Copernicus Publications on behalf of the European Geosciences Union. 
to as BCM2) presented here, MICOM has been coupled to the GELATO (Salas-Melia, 2002) dynamic and thermodynamic sea-ice model. In addition, MICOM has been modified in a number of ways since the original version of the model. These changes include among other things a new pressure gradient formulation and the introduction of incremental remapping for tracer advection, which has improved the ocean circulation in many respects compared to the original version of the model.

The aim of this paper is to give an overview of BCM2 and present results from a multi-century run for pre-industrial times. The mean climate states of the atmosphere, ocean and sea-ice for this period are described and validated against available observations. Another multi-century pre-industrial simulation with BCM2 that incorporates an intermediate complexity terrestrial and oceanic carbon cycle model, has also been carried out. Results from this simulation will be presented in a separate paper (Tjiputra et al., 2009). In this study, however, the carbon cycle model has not been included. The paper is organized as follows: in Sect. 2 the different model components are described in more detail. In Sect. 3 the spin-up procedures and design of the experiment are presented. The results are given in Sect. 4. Finally, the results are discussed and summarized in Sect. 5 .

\section{Model description}

\subsection{The atmosphere model}

The atmosphere component is the spectral atmospheric general circulation model ARPEGE-CLIMAT3 from METEO FRANCE (Déqué et al., 1994). The ARPEGE version applied in this study is described in detail in Furevik et al. (2003). However, its major features are briefly summarized here. In ARPEGE, the representation of most model variables is spectral (i.e. scalar fields are decomposed on a truncated basis of spherical harmonic functions). In the present study, ARPEGE is run with a truncation at wave number 63 $\left(\mathrm{T}_{\mathrm{L}} 63\right)$, and a time step of $1800 \mathrm{~s}$. All the physics and the treatment of model nonlinear terms require spectral transforms to a Gaussian grid. This grid (about $2.8^{\circ}$ resolution in longitude and latitude) is reduced near the poles to give an approximately uniform horizontal resolution (on the target sphere) and to save computational time. The vertical hybrid coordinate follows the topography in the lower troposphere, but becomes gradually parallel to pressure surfaces with increasing height. In this study, a total of 31 vertical levels are employed, ranging from the surface to $0.01 \mathrm{hPa}$.

The physical parametrization is divided into several explicit schemes, each calculating the flux of mass, energy and/or momentum due to a specific physical process. Differences from the model description in Déqué et al. (1994) include a convective gravity drag parametrization (Bossuet et al., 1998), a new snow scheme (Douville et al., 1995), a re- fined orographic gravity wave drag scheme (Lott and Miller, 1997; Lott, 1999; Catry et al., 2008) and modifications in deep convection and soil vegetation schemes.

The vertical diffusion scheme is a first order eddyviscosity scheme (Louis, 1979; Louis et al., 1982; Geleyn, 1988), which is popular in global models because of its simplicity and physical clarity. In the original version of the scheme a feedback could be activated in the case of a very cold surface. A cooling surface involved an increase in the stability, which in turn would prevent any heating by the atmosphere. This would accelerate the cooling until reaching a radiative balance which could be very cold in the polar night. This phenomenon led to a significant cold bias in the global temperature in earlier versions of BCM. To avoid the phenomenon a limitation has been added to the Richardson number:

if $R i>0$ then $R i \leftarrow \frac{R i}{1+R i / R i_{c r}}$ and $U_{\text {ric }}=\frac{1}{R i_{c r}}$,

where $R i_{c r}$ is an upper limit for positive Richardson numbers. The standard value for $U_{\text {ric }}$ is 0 , which comes to not applying the above limitation. In the present version of BCM a value of 1.2 is used for $U_{\text {ric }}$.

In ARPEGE there is a mass drift due to the nonconservative form of the discretized continuity equation (M. Deque, personal communication, 2009). In order to correct for this the following method has been used: every $6 \mathrm{~h}$ the partial pressure of dry air averaged over the globe is calculated. This value is then compared with the value 983.2 $\mathrm{hPa}$, which is the ERA40 average value. The difference (loss or gain of mass) is then added to the surface pressure uniformly (less than $0.1 \mathrm{hPa}$ per month). With this correction total air mass can have a seasonal cycle or a long-term drift (due to variations in water vapor content), but no drift due to non-conservation due to the equation. The drawback, however, is the unform correction, since the sources and sinks may be local.

The ARPEGE model includes the effect of different kinds of aerosols: continental, marine (due to emissions of sea salt), desert dust, black carbon, tropospheric sulphate aerosols and stratospheric aerosols (due to volcanic eruptions). The horizontal distribution of the first four are held constant at their default values which are defined according to Tanre et al. (1984). The concentrations of sulphate aerosols are set at pre-industrial 1850 values based on data provided for by Boucher and Pham (2002) for the IPCC AR4 simulations. The direct effect of all these aerosol types has been taken into account, but no indirect effects have been considered in this version of the model. Volcanic aerosols have been implemented into the model, and standard Mount Pinatubo test simulations have been carried out (Otterå, 2008). These experiments reveal that the atmospheric circulation in ARPEGE reacts realistically to imposed volcanic aerosols. In this study, however, the stratospheric aerosols are kept constant at their default background values. 


\subsection{The ocean model}

The numerical methods and thermodynamics of MICOM are documented in Bleck and Smith (1990) and Bleck et al. (1992). In the version of MICOM used in this study, several important aspects deviate from the original model and the one used in the original version of BCM (i.e. Furevik et al., 2003). The original MICOM uses potential density with reference pressure at $0 \mathrm{db}$ as vertical coordinate ( $\sigma_{0}$-coordinate). This ensures that the very different flow and mixing characteristic in neutral and dia-neutral directions is well represented near the surface since isopycnals and neutral surfaces are similar near the reference pressure. For pressures that differ substantially from the reference pressure, this condition does not hold. In this study, a reference pressure of $2000 \mathrm{db}$ is used. The non-neutrality of the isopycnals in the world ocean is then reduced compared to having the reference pressure at the surface (McDougall and Jackett, 2005).

Furthermore, for the advection of tracers (potential temperature, salinity and passive tracers) and layer thickness, the current version of MICOM uses incremental remapping (Dukowicz and Baumgardner, 2000) adapted to the grid staggering of MICOM. The algorithm is computationally rather expensive compared to other second order methods with limiters for one tracer or age tracer, but the cost of adding additional tracers and age tracers is modest. In contrast to the original transport methods of MICOM, incremental remapping ensures monotonicity of the tracers.

Traditionally, MICOM expresses the pressure gradient force as a gradient of a potential on an isopycnic surface, as such a formulation has favorable numerical properties (Hsu and Arakawa, 1990). This is only accurate if the density can be considered as a function of potential density and pressure alone, which is not the case (de Szoeke, 2000). There have been several attempts to modify the MICOM pressure gradient formulation in order to incorporate a more accurate representation of density (Sun et al., 1999; Hallberg, 2005). The formulation used in the new version of MICOM, is based on the formulation of Janic (1977) where the pressure gradient is expressed as a gradient of the geopotential on a pressure surface. This allows a more accurate representation of density in the pressure gradient formulation.

The treatment of diapycnal mixing follows the standard MICOM approach of a background diffusivity dependent on the local stability and implemented using the scheme of McDougall and Dewar (1998). To incorporate shear instability and gravity current mixing, a Richardson number dependent diffusivity has been added to the background diffusivity. This has greatly improved the water mass characteristics downstream of overflow regions. Lateral turbulent mixing of momentum and tracers is parameterized by Laplacian diffusion, and layer interfaces are smoothed with biharmonic diffusion.

With the exception of the equatorial region, the ocean grid is almost regular with horizontal grid spacing approximately $2.4^{\circ} \times 2.4^{\circ}$. In order to better resolve the dynamics near the
Equator, the horizontal spacing in the meridional direction is gradually decreased to $0.8^{\circ}$ along the Equator. The model has a stack of 34 isopycnic layers in the vertical, with potential densities ranging from 1029.514 to $1037.800 \mathrm{~kg} \mathrm{~m}^{-3}$, and a non-isopycnic surface mixed layer on top providing the linkage between the atmospheric forcing and the ocean interior.

\subsection{The sea-ice model}

There are currently two dynamic and thermodynamic sea-ice modules available for BCM2, both of which are handled as subroutine calls from MICOM. Originally, the sea-ice model developed at Nansen Environmental and Remote Sensing Center (NERSC) was used. This model consists of one ice and one snow layer assuming a linear temperature profile in each layer, and the thermodynamics follows Drange and $\mathrm{Si}$ monsen (1996). The dynamic part of the model is based on the viscous-plastic rheology of Hibler (1979) with the modifications and implementation of Harder (1996).

The sea-ice model used in this study, however, is GELATO, a sea-ice model that was developed at METEO FRANCE and described in detail by Salas-Melia (2002). As opposed to the original NERSC model, GELATO is a multi-category sea-ice model (thickness dependent), allowing a more precise treatment of thermodynamics. Specifically, growth rates of ice slabs of different thicknesses, subjected to the same oceanic and atmospheric forcings, can vary considerably from one category to another. Within a grid cell, sea-ice is described as a collection of ice slabs, and each slab is described by its thickness, the fraction of the grid cell it covers, its enthalpy, and the amount of snow covering it. For every thickness category the model computes sea-ice velocities solving the stress tensor as described in Hunke and Dukowicz (1997) and then applies a non-diffusive advection scheme that conserves the first and second moments of the advected fields (Prather, 1986). Redistribution of sea-ice due to rafting and ridging processes is simulated according to the theory developed by Thorndike et al. (1975).

In order to model vertical heat diffusion in an ice-snow slab, a vertical discretization is defined, considering four layers in the ice part of the slab and one level snow. Solving of this diffusion scheme is implicit in time. All model equations are solved on an Arakawa B-grid which shares its grid points with the $\mathrm{C}$-grid of the ocean model. A linear interpolation between the two grids is performed internally by the sea-ice model.The rest of the thermodynamics, including snow aging scheme is treated explicitly (Salas-Melia, 2002).

\subsection{The coupler}

The OASIS coupler (version 2.2) has been used to couple the atmosphere and ocean models. It was developed at the National centre for climate modeling and global change (CERFACS), Toulouse, France (Terray and Thual, 1995; Terray 
Table 1. List of variables that are being exchanged via the coupler, OASIS2.2.

\begin{tabular}{ll}
\hline \multicolumn{1}{c}{ Ocean-Atmosphere } & \multicolumn{1}{c}{ Atmosphere-Ocean } \\
\hline sea surface temperature & non-solar heat flux \\
sea ice extent & solar heat flux \\
albedo & total water flux \\
zonal sea surface velocity & runoff \\
meridional sea surface velocity & albedo \\
& zonal wind stress \\
& meridional wind stress \\
& non-solar heat flux derivative \\
& liquid precipitation \\
& solid precipitation \\
& surface temperature \\
& total cloud cover \\
&
\end{tabular}

et al., 1995), and is currently in use in many climate centers. The main tasks of OASIS are to synchronize the models, so the fastest running model can wait for the other model until they are both integrated a prescribed time interval (1 day); to read the exchange fields from the source model; to apply weight coefficients for the interpolations; and to finally write the new fields to the target model. A list of the fields being exchanged via the coupler is given in Table 1 .

\section{Experimental design}

The initialization of coupled atmosphere-ocean climate models for historical simulations has been a long-standing problem in the climate model development communities. In particular, obtaining initial conditions for the ocean is quite a challenge since world-wide observational oceanic measurements are only available for near present-day. One technique that has often been used to initialize pre-industrial control simulations, is to reset the radiative forcing to near 1850 conditions using near present day Levitus oceanic initial conditions. However, a model coupled in this manner will, in general, suffer from climate drifts. In this study, we therefore use a method similar to the one outlined in Stouffer et al. (2004), where the radiative forcing was run backwards in time from the present to pre-industrial (1850) levels, and then held constant at this level for 3-5 centuries. One of the advantages of this method compared to other methods is that it generates internally consistent pre-industrial conditions within the framework of the model (Stouffer et al., 2004).

The initial conditions for the pre-industrial (PI) control integration are obtained from the end of a 500 years, fourphase spin-up integration. In the first phase of the spin-up the ocean and sea-ice model were integrated together for approximately 100 years, forced with two consecutive cycles of daily NCEP/NCAR reanalysis fields (Kalnay et al., 1996). The ocean was initialized with a climatological present-day hydrography (Steele et al., 2001) while the sea-ice was initialized with a climatological sea-ice extent and a constant thickness of one meter. The surface salinity was kept close to observations, while there was no adjustment of sea surface temperatures. The purpose of using a restart from an oceansea-ice spin-up was to avoid initializing the coupled model with an ocean at rest.

In the second phase, the coupled system was initialized with the final state of the ocean-sea-ice spin-up combined with an atmospheric state that was obtained from the end of a multi-year simulation with the atmosphere-only model. The model is not sensitive to the atmospheric initial condition, as the atmosphere equilibrates with the upper ocean on a relatively rapid time scale. Once coupled, the model was run without any form of flux adjustment on neither heat nor freshwater. The coupled system was then integrated for 200 years with constant, present-day (2000 AD) radiative conditions and with a solar constant value set at $1370 \mathrm{~W} \mathrm{~m}^{-2}$, which is somewhat higher than what is observed (about $1366 \mathrm{~W} \mathrm{~m}^{-2}$ ). However, in earlier runs with BCM2 a poor low-level atmospheric circulation (i.e. anomalously high pressure in the high northern regions described below) partly contributed to an excessive $\mathrm{NH}$ sea-ice extent in the model. In order to remedy this, the default value of the solar constant was increased from 1365 to $1370 \mathrm{~W} \mathrm{~m}^{-2}$. Even though this will likely not change the variability of the system, the use of a more physically accepted solar constant value is better and will be used in future development of the model system. Other forcings, such as the ice sheet topography, coastlines, soil and vegetation fields were all prescribed at present-day values.

In the third phase, following the method outlined in Stouffer et al. (2004), the radiative forcing conditions were then gradually changed to pre-industrial (1850 AD) values over a period of 50 years and then kept constant thereafter. Here, radiative forcings refer to changes in the trace gases only. The orbital parameters were prescribed to the reference values of $1950 \mathrm{AD}$. In the final spin-up phase the model was run for a further 150 years to allow the simulated climate to adjust, at least partially, to the new forcing regime. These last 150 years of the spin-up are discarded and not part of the analysis shown below. Thus, what is labeled as year 1 of the PI control simulation corresponds to a time 200 years after the gradual decrease in the radiative forcings were first introduced.

\section{Results}

A necessary condition for a reliable GCM prediction of regional climate change is that the control simulation should be fairly realistic. If features are positioned incorrectly, then any simulated shifts in these features may also be incorrect. Here, the control simulation for pre-industrial climate is assessed by comparison with climatological data. Climatological 
estimates are subject to errors due, among other things, to inadequate temporal or spatial sampling, observational biases, and different periods of observation. Thus, there may be substantial differences between climatologies, particularly in data-sparse regions.

\subsection{Model stability and climate drift}

After coupling the model components and starting from the set of initial conditions (see previous section), the climate system is typically not in equilibrium, and undergoes a drift toward a more equilibrated state. The time series of globalmean SST is plotted in Fig. 1a. The model experiences drift for a considerable time during the integration, with a warming trend of about 0.05 degrees per century. As will be shown below this warming trend is related to a persistent positive radiative imbalance in the model. Thus, time series of globalmean surface air temperature (not shown) show a very similar behavior.

Another measure of the drift is the top-of-the-atmosphere (TOA) net radiative imbalance (incoming shortwave - outgoing longwave) shown in Fig. 1b. There is a persistent positive imbalance of about $2.5 \mathrm{~W} \mathrm{~m}^{-2}$, indicating a net long-term gain of heat by the system. At the surface there is a net radiative imbalance (incoming shortwave - outgoing longwave - sensible heat - latent heat) of about $0.5 \mathrm{~W} \mathrm{~m}^{-2}$ (Fig. 1c). The radiation values gradually decrease over time as the system approaches a more equilibrated state. The radiative imbalance values are smaller at the surface than at the TOA (Fig. $1 \mathrm{~b}$ and c). This is largely due to the fact that the atmospheric dynamics in ARPEGE does not conserve energy (see above), and loses heat at a rate of approximately $2 \mathrm{~W} \mathrm{~m}^{-2}$. However, since this loss is quite uniform in time, it is not expected to be a significant issue in climate change experiments.

The heat imbalance at the surface is related to the time series of volume-mean ocean temperature averaged over the globe shown in Fig. 1d. There are small subsurface drifts (about $0.03 \mathrm{~K}$ per century) throughout the integration, reflecting the heat stored in the ocean, and it will likely take many centuries for the full-depth ocean to come into equilibrium.

The evolution of global sea surface salinity (SSS) over the 600 year integration period is shown in Fig. 2. In the model the water cycle budget is not entirely closed. There is therefore a drift towards higher global-mean salinity during the whole integration. The overall drift is about $0.01 \mathrm{psu}$ per century for the whole 600 year integration. Over $80 \%$ of this drift is balanced by growth of the Greenland and Antarctic ice sheets due to the absence of a calving scheme in the model. The remainder is likely due to the non-conservation of mass in the atmospheric model. Both the SST and SSS drifts are considerably reduced in the new version of BCM compared to the older version of the model (Furevik et al., 2003), despite the fact the older version used flux adjustments on both heat and freshwater. Several factors have con-

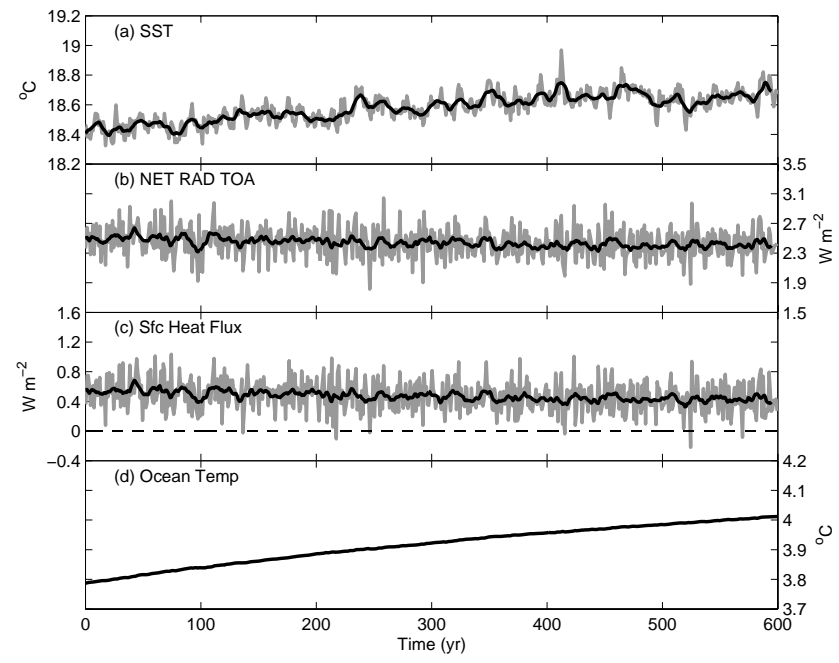

Fig. 1. Time series of annual-mean, global-mean quantities for the PI simulation. (a) SST, (b) TOA net radiative imbalance, (c) net heat flux at the surface, and (d) volume-mean temperature for the full-depth global ocean. The grey lines are annual-mean values, and the thick black lines are 10-year running means.

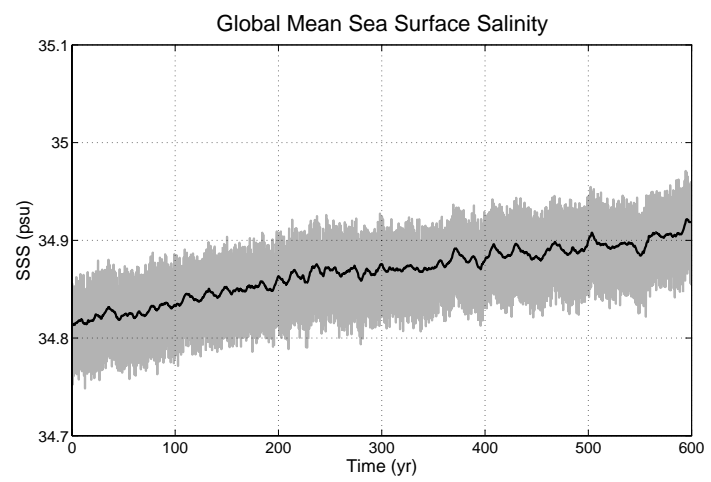

Fig. 2. Time series of annual-mean global-mean SSS (psu). The shaded region represents the spread of the monthly-mean data, while the thick black line is the 5-year running mean.

tributed to this, but improved conservation properties in the ocean model, MICOM, is probably the most important one.

The vertical distribution of the temperature and salinity biases (differences relative to year 1) of the global ocean is shown in Fig. 3. Generally the ocean becomes warmer and more saline during the integration. The radiative imbalance at the surface is likely the main reason for the warming trend. This imbalance will add heat to the deep ocean through convective mixing at high latitudes which will then gradually be spread around the globe by the thermohaline circulation. Below $4000 \mathrm{~m}$ it is interesting to note a cooling and a freshening early in the simulation, possibly indicating a changed stratification in the very deep ocean. This is not surprising as it will take many centuries for the deep ocean to reach equilibrium. 
(a)

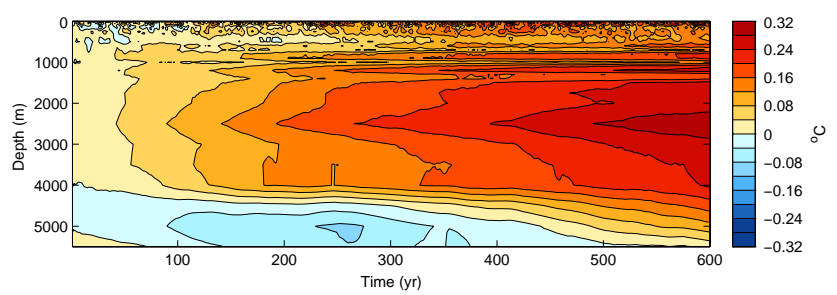

(b)

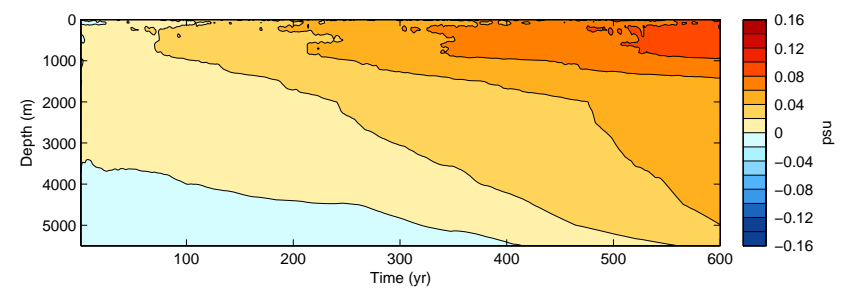

Fig. 3. Global ocean area-averaged differences relative to year 1 of the integration for (a) temperature $\left(^{\circ}\right)$ and (b) salinity (psu).
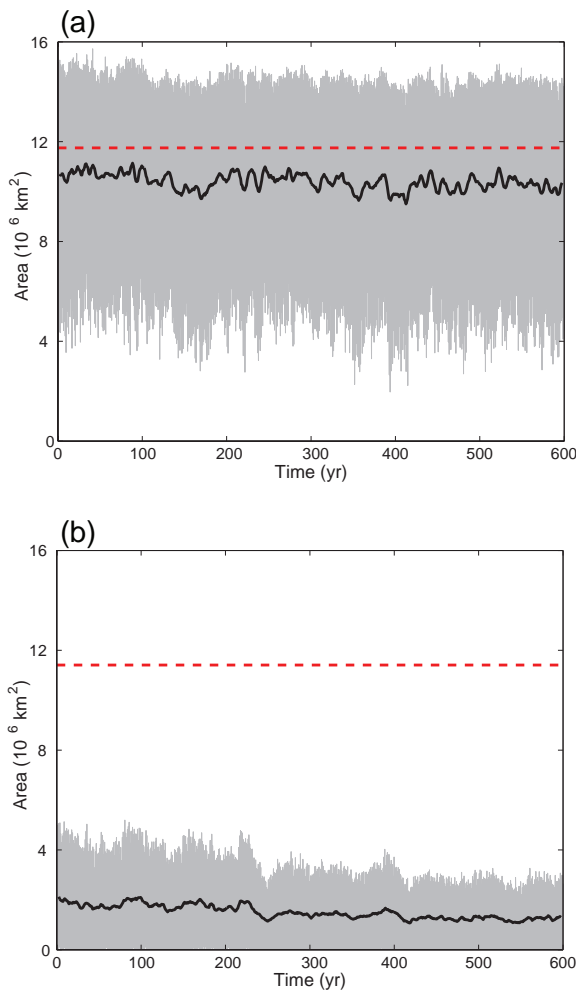

Fig. 4. Time series of the sea-ice cover for (a) $\mathrm{NH}$, and (b) $\mathrm{SH}$. The shaded regions represent the spread of the monthly mean data. The dashed red lines indicate the annual mean sea-ice areas between 1978-2003 based on satellite data (Cavalieri et al., 2003).

The total sea-ice extent in the Northern Hemisphere (NH) is close to the climatology both for the annualmean and the seasonal cycle, with almost no drift over the 600 year period (Fig. 4a). In the Southern Hemisphere
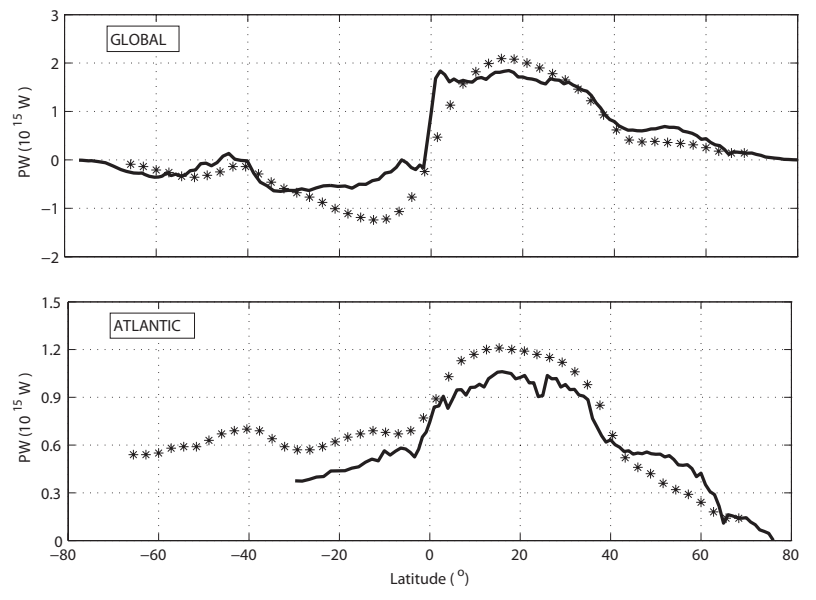

Fig. 5. Simulated northward oceanic heat transports (PW) for the global (top panel) and Atlantic (bottom panel) oceans. Asterisk symbols denote observational estimates based on Trenberth and Caron (2001).

$(\mathrm{SH})$, however, the sea-ice simulation is quite poor. The annual-mean sea-ice extent is only $1.76 \times 10^{6} \mathrm{~km}^{2}$ which is much less than the observational estimate of $11.5 \times 10^{6} \mathrm{~km}^{2}$ from Cavalieri et al. (2003).

We believe excessive mixing between the surface and the deep ocean in the Southern Ocean is the main cause for the warm bias and underestimation of sea ice extent in this region. The excessive mixing erodes the halocline and makes it difficult to maintain a fresh and cold surface layer required for wintertime freezing of sea-ice. The underestimation of sea-ice will in turn cause a warm bias in the model due to increased absorption of short-wave radiation.

Several factors might contribute to this excessive mixing. Firstly, the depth of MICOMs bulk mixed layer is found by balancing a turbulent kinetic energy budget according to Gaspar (1988). This parameterization generally tends to generate too deep mixed layer depths at high latitudes. Preliminary testing with the mixed layer depth parameterization of Oberhuber (1993) indicates much improved mixed layer depths at high latitudes compared to observations (de Boyer Montégut et al., 2004). Secondly, the ocean model uses isopycnic layers with potential densities estimated with a reference pressure at $2000 \mathrm{db}$. The profile with $2000 \mathrm{db}$ reference pressure gives a poor representation of stratification, even static instability, near the surface (Assmann et al., 2009). This makes it difficult for the model to represent a realistic halocline isolating the surface from the deeper ocean. Finally, in MICOM the brine rejected during freezing of sea-ice is placed in the surface layer. This tends to destabilize the water column near the surface. Several studies (Duffy and Caldeira, 1999; Sun and Bleck, 2006) indicate that a parameterization of saltplumes can contribute to the maintenance of a more realistic halocline in ocean models not resolving these plumes. 


\subsection{Time-mean simulation characteristics}

\subsubsection{Ocean transports of heat and volume}

The meridional transport of heat by the oceans is an important factor in the ability of models to simulate a realistic climate. The total simulated meridional transports of heat by the ocean, as well as an observational estimate, are shown in Fig. 5. For the entire globe, the northward transport in the $\mathrm{NH}$ poleward of $10^{\circ}$ is consistent with observational estimates from Trenberth and Caron (2001), but there appears to be insufficient southward transport of heat out of the Tropics in the model (Fig. 5, upper panel). The heat transport in the Atlantic is in reasonably good agreement with observational estimates, with just over $1 \mathrm{PW}$ maximum northward heat transport around $20^{\circ} \mathrm{N}$ (Fig. 5, lower panel). It should, however, be noted that significant uncertainties exist in the observational estimates of ocean heat transport.

A common diagnostic of the strength of the Atlantic thermohaline circulation is the Atlantic Meridional Overturning Circulation (AMOC). The simulated Atlantic meridional overturning streamfunction is characterized by a northward flow close to the surface, sinking at high latitudes and a southward flow at greater depths (Fig. 6a). Due to the choice of reference pressure at $2000 \mathrm{~m}$ and inclusion of thermobaric effects in the new version of MICOM, one can now see indications of a deep circulation cell of Antarctic bottom water extending into the Atlantic, a feature that was absent in previous versions of BCM. The overturning cell is also more shallow and realistic than in earlier versions of the model (Furevik et al., 2003; Otterå et al., 2003), and has a maximum value between 30 and $40^{\circ} \mathrm{N}$. The time series of the maximum value of the AMOC shows both decadal and interannual variability in the strength of the overturning around a mean of about 20 Sv (Fig. 6b). The mean value for the AMOC over the last 100 years at $24^{\circ} \mathrm{N}$ is about $16.6 \mathrm{~Sv}$, which is within the range of observational estimates of about $15.75 \pm 1.6 \mathrm{~Sv}$ (Ganachaud and Wunsch, 2000; Lumpkin and Speer, 2003) and other model estimates (Schmittner et al., 2005; Meehl et al., 2007). In the corresponding power spectrum of the AMOC time series peaks are seen at decadal (50-60 years) as well centennial (130-170 years) periods (Fig. 6c). To what extent the multidecadal AMOC variability simulated by BCM2 constitutes a true oscillatory mode of the coupled ocean-atmosphere system, is a question that will be addressed in future studies.

The mean simulated volume transports in the PI simulation for some key sections in the model are summarized and compared to estimates cited in the literature in Table 2. The simulated poleward transport of Atlantic Water (AW) across the Greenland-Scotland Ridge (GSR) sections amounts to about $10.8 \mathrm{~Sv}$, which is somewhat higher than the $8.0 \mathrm{~Sv}$ estimate based on observations from Hansen and Østerhus (2000). The southward transports across the GSR compare reasonably well with observational
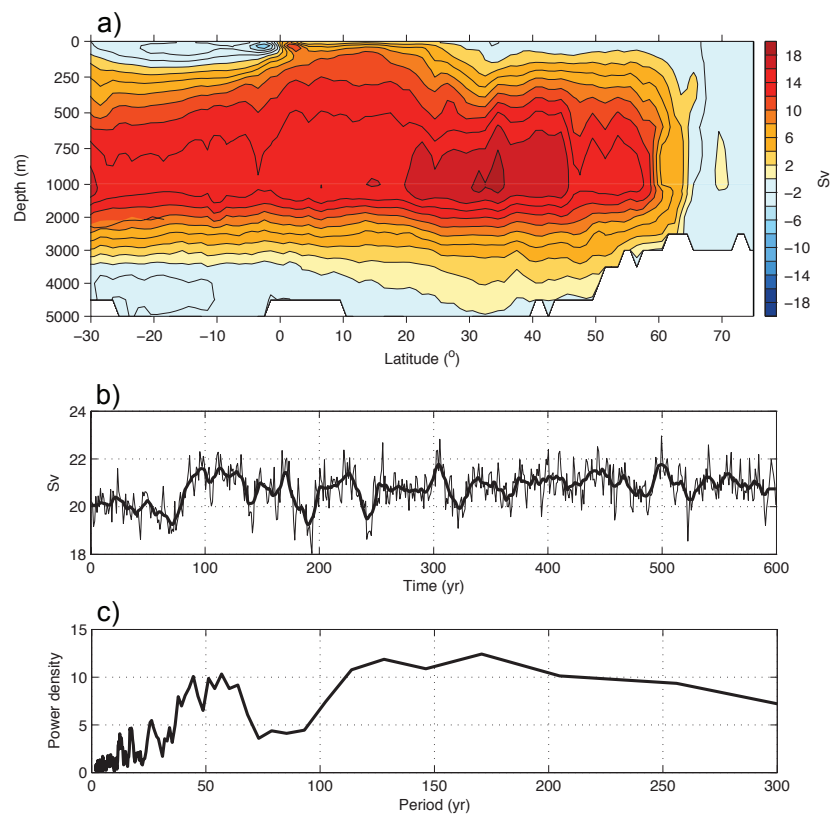

Fig. 6. (a) Annual-mean streamfunction (Sv) for the Atlantic ocean (years 501-600). (b) time evolution of the maximum of the Atlantic meridional overturning circulation for the PI control integration. (c) power spectrum of the detrended AMOC calculated using the Thomson multi-taper method.

estimates, although it should be mentioned that no attempt has been made to distinguish the different water masses in the simulated transport estimates.

The total northward transport of Atlantic and coastal waters into the Barents Sea is $2.9 \mathrm{~Sv}$ which is in good agreement with earlier estimates from Loeng et al. (1997) and more recent estimates from Schauer et al. (2002), Ingvaldsen et al. (2002) and Dickson et al. (2007). In addition, the poleward flow of Pacific Water through the Bering Strait of $1.5 \mathrm{~Sv}$ and the southward flow through the Canadian Archipelago of $1.7 \mathrm{~Sv}$ are both in reasonable agreement with observations (Dickson et al., 2007). The simulated northward and southward transports for the Fram Strait are 5.6 and $6.7 \mathrm{~Sv}$, respectively. Observational estimates of the transport through this section have large uncertainties attached to them due to the highly variable and complex circulation across this section, but recent estimates from Dickson et al. (2007) (4.5 and $6.2 \mathrm{~Sv}$ for the northward and southward transports, respectively) compare quite well with the model. In the $\mathrm{SH}$, the simulated net volume transport through the Drake Passage is 161.7 Sv, which is larger than the observational estimate of $134 \pm 11.2 \mathrm{~Sv}$ of Withworth and Peterson (1985). For the Indonesian Throughflow, the model simulates a net transport of $18.3 \mathrm{~Sv}$, which is higher than recent observational estimates of about $8.9 \pm 1.7 \mathrm{~Sv}$ (Wijffels et al., 2008).

Most of the transport estimates for the high northern latitudes are reasonably stable throughout the entire 600 year integration period. There are some positive trends in the northward transports through the Faroe Shetland Channel 
Table 2. Simulated (years 501-600) and observed estimates of ocean volume transports (Sv) through some key sections in the model domain. For the model estimates the trends are given in parentheses $\left(100 \mathrm{yrs}^{-1}\right) .{ }^{1}$ Dickson et al. (2007), ${ }^{2}$ Blindheim (1989), ${ }^{3}$ Hansen and $\emptyset$ sterhus (2000), ${ }^{4}$ Withworth and Peterson (1985) and ${ }^{5}$ Wijffels et al. (2008).

\begin{tabular}{lllllll}
\hline & \multicolumn{3}{c}{ PI simulation } & \multicolumn{3}{c}{ Observed } \\
& N/E & S/W & Net & N/E & S/W & Net \\
\hline Ocean transports (Sv) & & & & & & \\
Bering Strait & $1.5(0.01)$ & 0 & $1.5(0.01)$ & $0.8^{1}$ & 0 & 0.8 \\
Canadian Arch. & 0 & $1.7(0.03)$ & $1.7(0.03)$ & 0 & $1.5^{1}$ & 1.5 \\
Fram Strait & $5.6(0.24)$ & $6.7(0.24)$ & $1.1(0)$ & $4.5^{1}$ & $6.2^{1}$ & 1.7 \\
Barents Opening & $2.9(0.03)$ & $1.6(0.01)$ & $1.3(0.02)$ & $2.2^{1}$ & $1.2^{2}$ & 1.0 \\
Denmark Strait & $1.8(-0.01)$ & $5.1(0.02)$ & $3.3(0.03)$ & $1.0^{3}$ & $4.3^{3}$ & 3.3 \\
Iceland-Faroe & $3.8(0)$ & $1.6(0.03)$ & $2.2(-0.03)$ & $3.3^{3}$ & $1.0^{3}$ & 2.3 \\
Faroe-Scotland & $5.2(0.14)$ & $4.4(0.05)$ & $0.8(0.09)$ & $4.3^{3}$ & $4.5^{3}$ & -0.2 \\
North Sea Opening & $1.9(0.01)$ & $1.3(0.02)$ & $0.5(-0.01)$ & $\mathrm{n} / \mathrm{a}$ & $\mathrm{n} / \mathrm{a}$ & $\mathrm{n} / \mathrm{a}$ \\
Drake Passage & $167.3(4.3)$ & $5.6(0.1)$ & $161.7(4.2)$ & $\mathrm{n} / \mathrm{a}$ & $\mathrm{n} / \mathrm{a}$ & $134.0^{4}$ \\
Indonesian Arch. & $5.9(0)$ & $24.2(0.2)$ & $18.3(0.2)$ & $\mathrm{n} / \mathrm{a}$ & $\mathrm{n} / \mathrm{a}$ & $8.9^{5}$ \\
\hline
\end{tabular}

and further north through the Fram Strait. However, for the Fram Strait this trend is counteracted by a similar positive trend in the southward transport making the net transport quite stable. The transport through the Drake Passage is, however, not stable. There is a positive drift of about $4 \mathrm{~Sv}$ per century throughout the integration, which underlines the problems BCM2 has in the Southern Ocean. This is most likely a due to slow oceanic adjustment to the changed seaice cover for this region.

\subsubsection{Ocean surface}

The time-mean errors in the PI simulation of sea surface temperature (SST) and sea surface salinity (SSS) are shown in Fig. 7 along with their global root mean square values. The largest errors in SST compared to the Levitus data (Levitus and Boyer, 1994) are seen in the Southern Ocean (Fig. 7a) and are mainly caused by negative sea-ice biases here. The extratropical northern Pacific is slightly too cold, while the northern North Atlantic, including the subpolar gyre, is too warm. For the SSS, the largest errors compared to the Levitus data (Levitus et al., 1994) are found in the poorly sampled Arctic Ocean. In the central Arctic Ocean the ocean surface is too saline by about $2 \mathrm{psu}$, while negative salinity anomalies of 1-2 psu can be found in the Transpolar Drift (Fig. 7b). In the northern Pacific and Indian Oceans the waters are generally too saline (1-2 psu) compared to the Levitus data, while a fresh bias (about 1 psu) can be found in the sub-tropical South Atlantic. In the Southern Ocean and the North Atlantic, the errors are relatively small in SSS.

The sea-ice thickness distributions and the surface ocean velocities for the $\mathrm{NH}$ and $\mathrm{SH}$ are shown for the PI simulation in Fig. 8. In March, the simulated sea-ice extent compares well with observations except for the Labrador Sea region where there is too little sea-ice (Fig. 8a). In

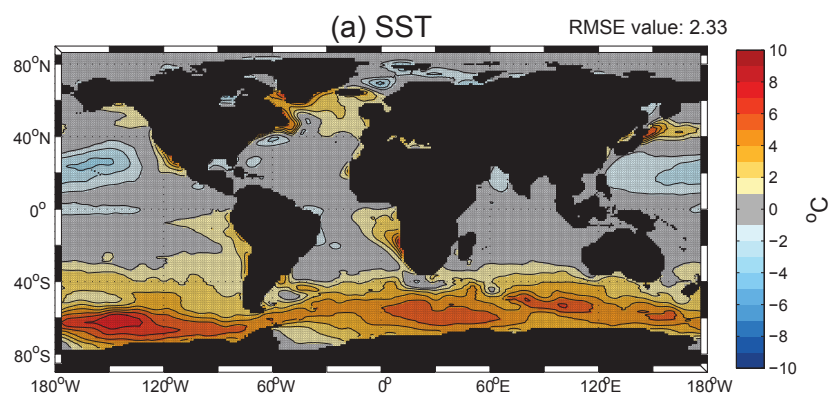

(b) SSS

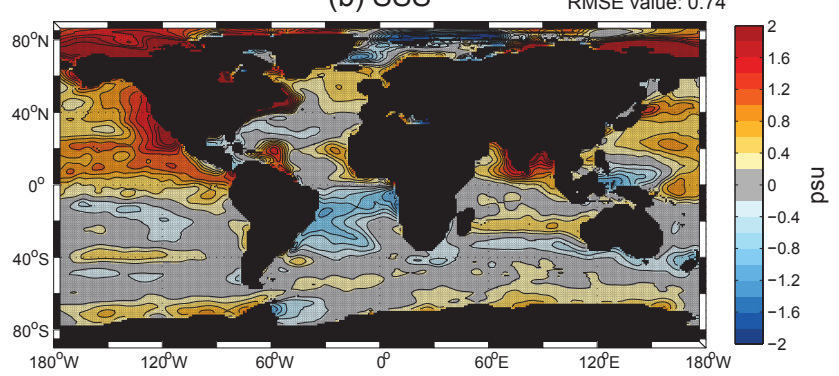

Fig. 7. Errors in simulation of (a) SST and (b) SSS for the PI simulation compared to Levitus data. The root mean square error (RMSE) is indicated in the upper right corner of each panel. Contour interval is $1^{\circ} \mathrm{C}$ and $0.2 \mathrm{psu}$ for (a) and (b), respectively.

September, the sea-ice extent is generally too small compared to the observations (Fig. 8b). A general problem for both seasons, but in particular for the summer season, is that the sea-ice is quite thin (about $1-1.5 \mathrm{~m}$ for the summer). This may adversely affect projections of Arctic sea-ice change under increasing greenhouse gas concentrations and changes in the orbital configuration. The annual-mean seaice extent for the last 100 years is $10.3 \times 10^{6} \mathrm{~km}^{2}$ which is somewhat below the observational estimate of $11.7 \times 10^{6} \mathrm{~km}^{2}$ from Cavalieri et al. (2003). 
(a) $\mathrm{NH}$, March

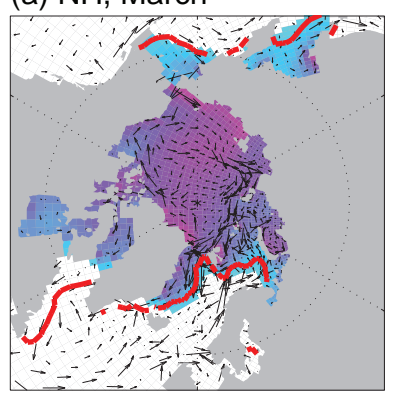

(c) $\mathrm{SH}$, March

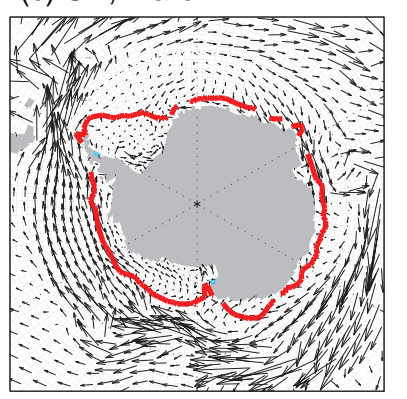

$\varepsilon$

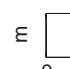

(b) $\mathrm{NH}$, September

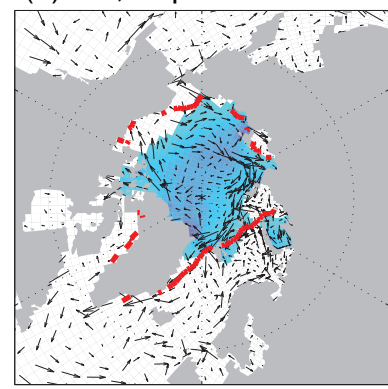

(d) $\mathrm{SH}$, September

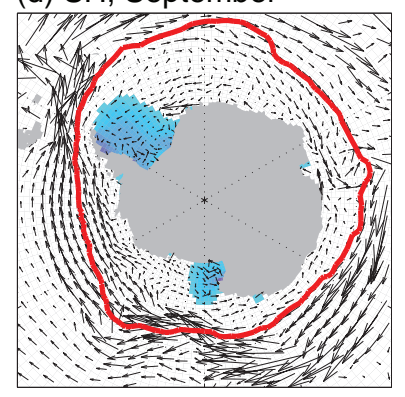

$0.1 \mathrm{~m} \mathrm{~s}^{-1}$

Fig. 8. Simulated sea-ice thickness (m) and surface ocean velocity $\left(\mathrm{m} \mathrm{s}^{-1}\right)$ in the PI simulation for (a) NH, March, (b) NH, September, (c) SH, March and (d) SH, September. The observational estimate for sea ice extent (from NCEP) is indicated by the thick red line.

For the SH, the simulated sea ice does not compare well with observations neither in summer nor in winter (Fig. 8c and $\mathrm{d}$ ). The poor sea ice simulation is likely related to the parametrization of the mixed layer turbulent kinetic energy closure (see discussion above). The current parametrization leads to a mixed layer that is too deep in the Southern Ocean, which in turn makes it hard to maintain a realistic sea-ice cover here. The sea-ice biases in the $\mathrm{SH}$ are a serious problem in the model, and are an important area for further model development.

The model manages to capture the major features of the observed flow fields in the North Atlantic-Arctic region and the Southern Ocean (Fig. 8). In northern North Atlantic the ocean circulation is dominated by the sub-polar gyre, while the general surface ocean circulation within the Nordic Seas is dominated by the warm and saline Norwegian Atlantic Current to the south and east, and the cold and fresh East Greenland Current to the north and west (Fig. 8a and b). In the Arctic Ocean, the circulation is dominated by the Beaufort Gyre (a roughly circular current flowing clockwise within the surface waters of the Beaufort Sea) and the Transpolar Drift (the major current flowing into the Atlantic Ocean from the eastern Arctic). In the Southern Ocean the ocean circulation is dominated by the Antarctic Circumpolar Current flowing from west to east around Antarctica (Fig. 8c and

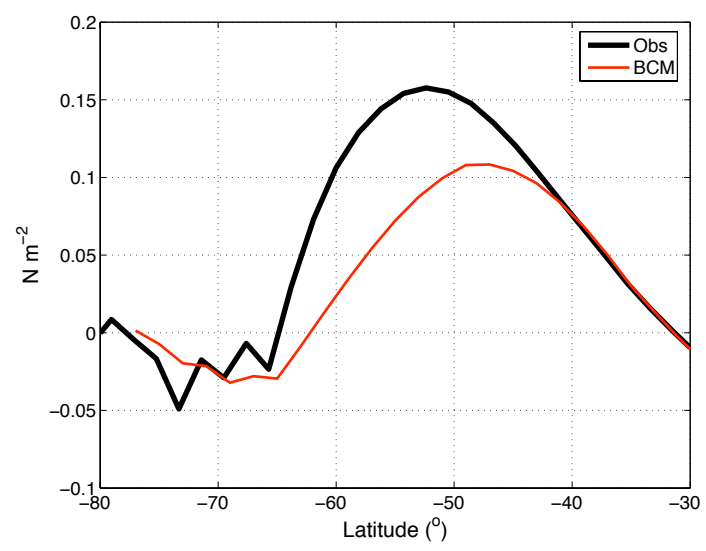

Fig. 9. Zonally averaged wind-stress $\left(\mathrm{N} \mathrm{m}^{-2}\right)$ from observations based on NCEP-NCAR reanalysis (black line) and BCM2 (red line).

d). In addition, two clockwise gyres are seen to swirl in the vicinity of the Weddell and Ross Seas.

The distribution and magnitude of the simulated wind stress over the Southern Ocean compares relatively poorly with observations (Fig. 9). The peak zonally averaged wind stress is shifted equatorward relative to the observations (from NCEP long-term mean), and is about $30 \%$ weaker than observed. A recent intercomparison of the Southern Ocean circulations in the IPCC coupled climate models revealed that many of the models suffers from similar problems as BCM (Russell et al., 2006). In particular, all but a few of the models show an equatorward shift of the peak westerlies in the Southern Ocean.

\subsubsection{Atmospheric circulation and precipitation}

The model successfully reproduces the main features of the sea level pressure (SLP) distribution as depicted by the NCEP reanalysis (Kalnay et al., 1996), but there are errors in the details (Fig. 10). In December-January-February (DJF, Fig. 10a, c, and e) the Icelandic low is not deep enough and the associated trough does not extend far enough eastnortheastward due to excessive pressure over the Arctic. The mid-latitude circulation in the Atlantic and Eurasia regions is generally well reproduced. In the Pacific sector, the Aleutian low is somewhat underestimated in the model, while the pressure over North America is overestimated compared to the NCEP reanalysis. In the $\mathrm{SH}$, the circumpolar trough is shallower than observed leading to anomalously weak surface winds there.

In June-July-August (JJA, Fig. 10b, d, and f) the SLP distribution is generally well reproduced in the mid-latitudes except for the North Pacific where the model produces anomalously high pressures. As was the case for the winter circulation, the simulated pressure north of $60^{\circ} \mathrm{N}$ is much too high compared to NCEP data. In the SH, the pressure in the circumpolar trough is also higher than observed. The relatively 
(a) NCEP: DJF

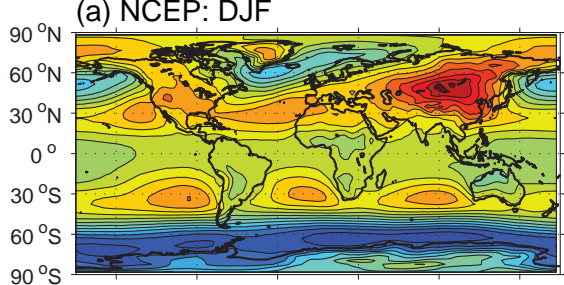

(c) BCM: DJF

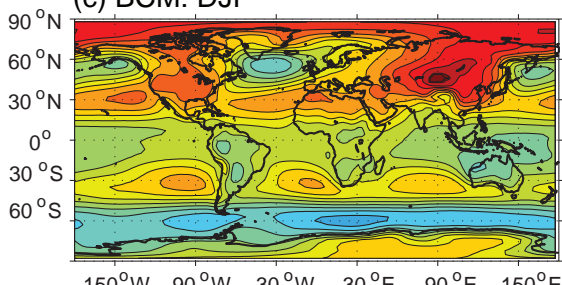

$150^{\circ} \mathrm{W} \quad 90^{\circ} \mathrm{W} \quad 30^{\circ} \mathrm{W} \quad 30^{\circ} \mathrm{E} \quad 90^{\circ} \mathrm{E} \quad 150^{\circ} \mathrm{E}$

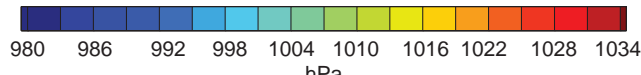

(e) BCM - NCEP: DJF

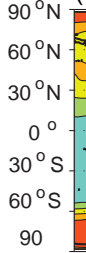

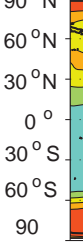

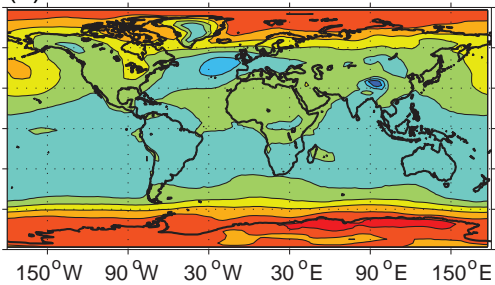

(f) BCM - NCEP: JJA

(b) NCEP: JJA

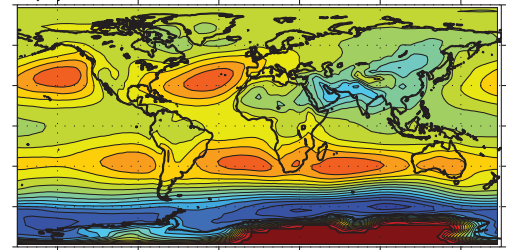

(d) BCM: JJA
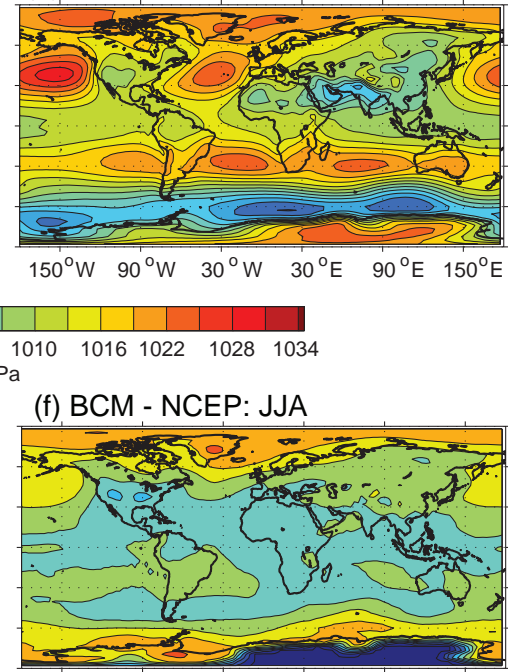

$150^{\circ} \mathrm{W} \quad 90^{\circ} \mathrm{W} \quad 30^{\circ} \mathrm{W} \quad 30^{\circ} \mathrm{E} \quad 90^{\circ} \mathrm{E} \quad 150^{\circ} \mathrm{E}$

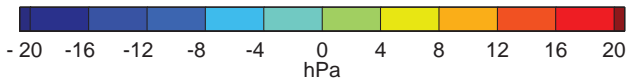

Fig. 10. Observed (based on NCEP-NCAR reanalysis) and simulated SLP (hPa). (a) NCEP (DJF), (b) NCEP (JJA), (c) BCM (DJF), (d) BCM (JJA), (e) BCM-NCEP (DJF) and (f) BCM-NCEP (JJA).

poor simulation of SLP at high latitudes in the model has been a persistent problem with the current model system. Part of the problem in the $\mathrm{SH}$ is related to the poor sea-ice distribution (see above). A negative zonal bias in the Antarctic sea-ice extent during winter will give massive anomalous heat fluxes that produce warm marine air in the Antarctic region. This results in weaker, and poleward shifted temperature gradients. According to the thermal wind balance, the pressure gradients will be reduced and this in turn will contribute to a positive bias in the circumpolar Antarctic low, particularly during JJA. As the negative sea-ice bias is largest in winter, the consequences mentioned will also contribute to a reduced seasonal variability in the mass and wind fields. The reasons for the positive SLP anomalies in high northern latitudes are less clear. It could be noted, however, that the inclusion of the refined gravity wave drag parametrization from version 4 of ARPEGE (see above) has not significantly improved the high northern SLP distribution.

Figure 11 shows the annual zonal-mean zonal wind for the PI simulation compared to NCEP data. In the observations, there are two main jet streams at the polar latitudes, one in each hemisphere (Fig. 11a). The peaks of the jet streams are found just below the tropopause at about $200 \mathrm{hPa}$ and
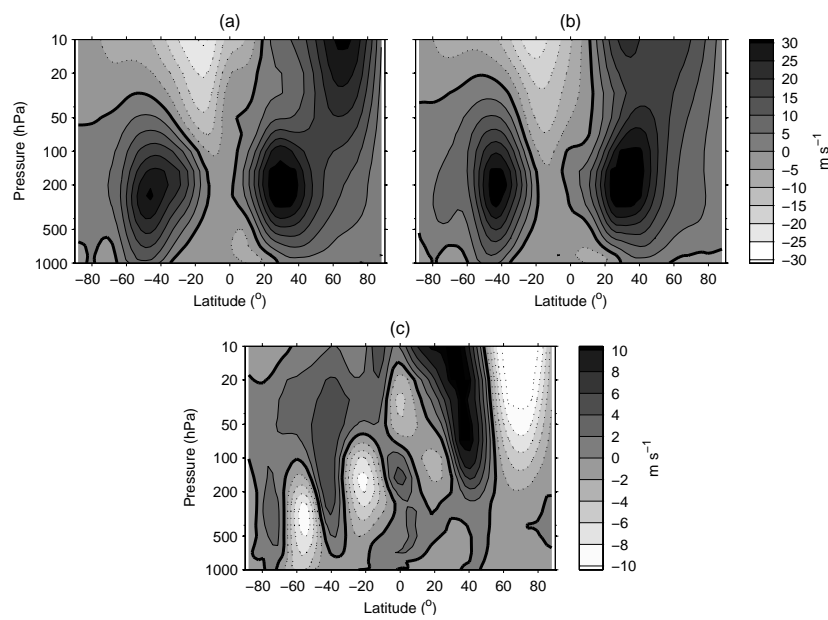

Fig. 11. Annual-mean zonal-mean of zonal wind $\left(\mathrm{m} \mathrm{s}^{-1}\right)$. (a) observational estimates from NCEP-NCAR reanalysis, (b) PI control integration (years 501-600), and (c) PI-observations.

located around $30-40^{\circ} \mathrm{N}$ for the $\mathrm{NH}$, and around $40-50^{\circ} \mathrm{N}$ for the $\mathrm{SH}$. The stratosphere is characterized by an easterly jet that extends across the Equator, and a westerly jet in northern high latitudes with a center of action around $60^{\circ} \mathrm{N}$. 
Generally, the position and strength of the tropospheric jets are reasonably well simulated (Fig. 11b). In the SH, however, the reanalysis exhibits a narrower westerly jet than the PI simulation. This points to a reduced seasonal variability and is consistent with the arguments given above. In the NH, the tropospheric and stratospheric parts of the westerly jet are found to be too vertically aligned. In particular, the strength of the stratospheric vortex is clearly underestimated in the model, with the center of action shifted too far to the south compared to observations (Fig. 11c).

Precipitation is highly variable both spatially and temporally, and it is difficult to obtain robust measurements globally, especially over the oceans. Observational data from Legates and Willmott (1990) and Spencer (1993) show that the precipitation is heaviest along the intertropical convergence zone, over warm oceanic regions and in monsoonal areas (Fig. 12a). Arid regions tend to occur in regions of descending air, and in polar regions, where the cold air also reduces the capacity of the atmosphere to hold moisture. The PI simulation reproduces the main precipitation patterns including those associated with the mid-latitude storm tracks and the continental monsoons. However, there is a general tendency to underestimate the amount of precipitation compared to the observations, especially over the ocean (Fig. 12b).

\subsection{Variability characteristics}

A few of the characteristics of the model-simulated interannual variability are presented here (variability on multidecadal time-scales will be investigated in future papers). One of the strongest natural modes of variability in the global climate system is the El Niño-Southern Oscillation (ENSO). Apart from ENSO, the dominant patterns of global-scale climate variability are the annular modes in both hemispheres (Limpasuvan and Hartmann, 1999; Thompson and Wallace, 2000), often referred to as the Northern and Southern Annular Modes (NAM and SAM for the NH and SH, respectively). In the following sections, these modes of variability will be analyzed based on the SLP and surface air temperature (T2m) fields.

\subsubsection{The ENSO mode}

The simulated monthly mean Niño3-index provides an estimate of El Niño-related temperature variability in the model. The Niño3-index is calculated as the mean SST over the eastern tropical Pacific (the region bounded by $150^{\circ} \mathrm{W}$ to $90^{\circ} \mathrm{W}$, $5^{\circ} \mathrm{S}$ to $5^{\circ} \mathrm{N}$ ) and is shown in Fig. 13a for the model and the NCEP-NCAR reanalysis fields. The standard deviation of the Niño3-index in $\mathrm{BCM} 2$ is $0.62^{\circ} \mathrm{C}$, compared to the observed $0.84^{\circ} \mathrm{C}$ in the NCEP-NCAR data. The reason for the underestimation of the Niño3 variability is not clear, but it could be related to the resolution being too coarse in the equatorial Pacific in the ocean model. The model skewness (a) OBS

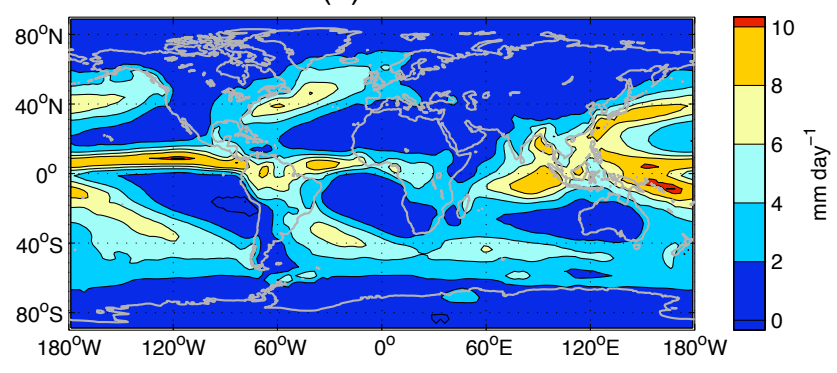

(b) BCM

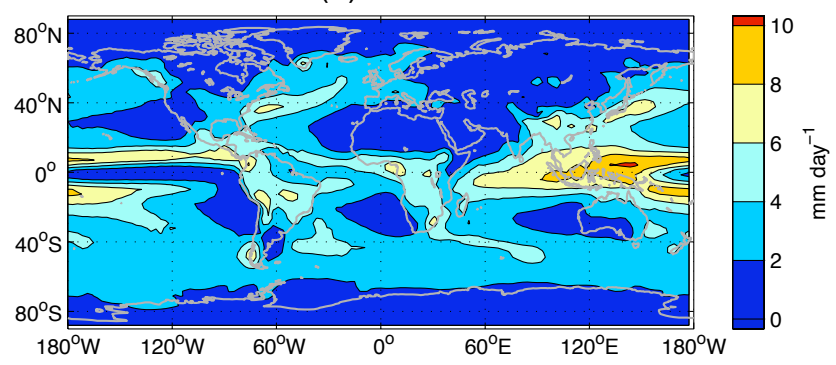

Fig. 12. Annual mean precipitation $\left(\mathrm{mm} \mathrm{day}^{-1}\right)$. (a) observational estimate from Legates and Willmott (1990) and Spencer (1993), and (b) PI control integration (years 501-600).
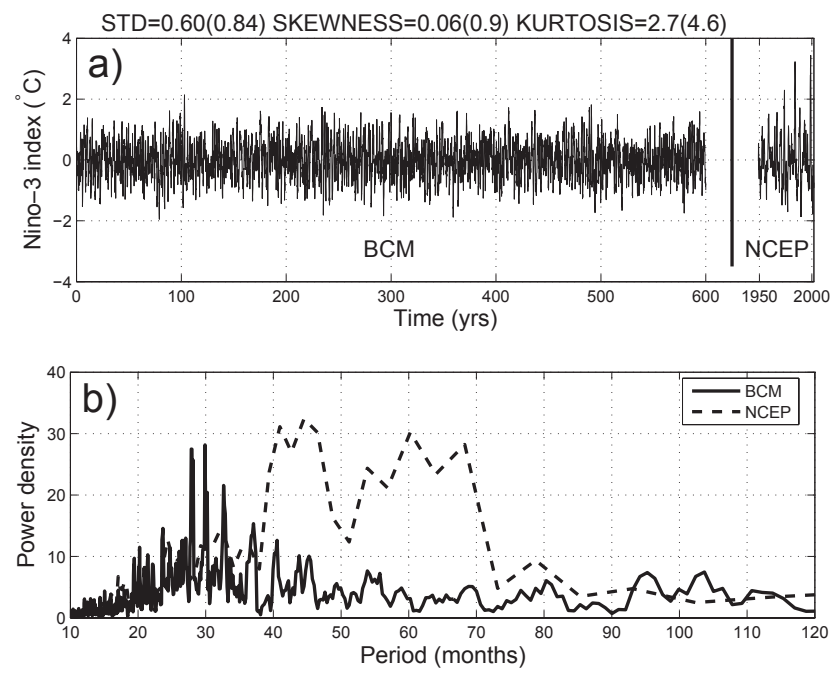

Fig. 13. (a) time series of the Niño3 indices for BCM 2 and NCEPNCAR. The indices are calculated as the average SSTs in the area $150^{\circ} \mathrm{W}$ to $90^{\circ} \mathrm{W}, 5^{\circ} \mathrm{S}$ to $5^{\circ} \mathrm{N}$. The standard deviation, skewness, and kurtosis of the two indices are also shown (observed estimate in parenthesis). (b) power spectral density for the Niño3 indices for BCM2 (solid line) and NCEP-NCAR (dashed line) calculated using the Thomson multi-taper method.

and kurtosis are also much smaller than in the observations. This suggests that the model is underestimating the nonlinerarity in ENSO. The power spectra of the observed and simulated Niño3-indices show that BCM2 has little power in 

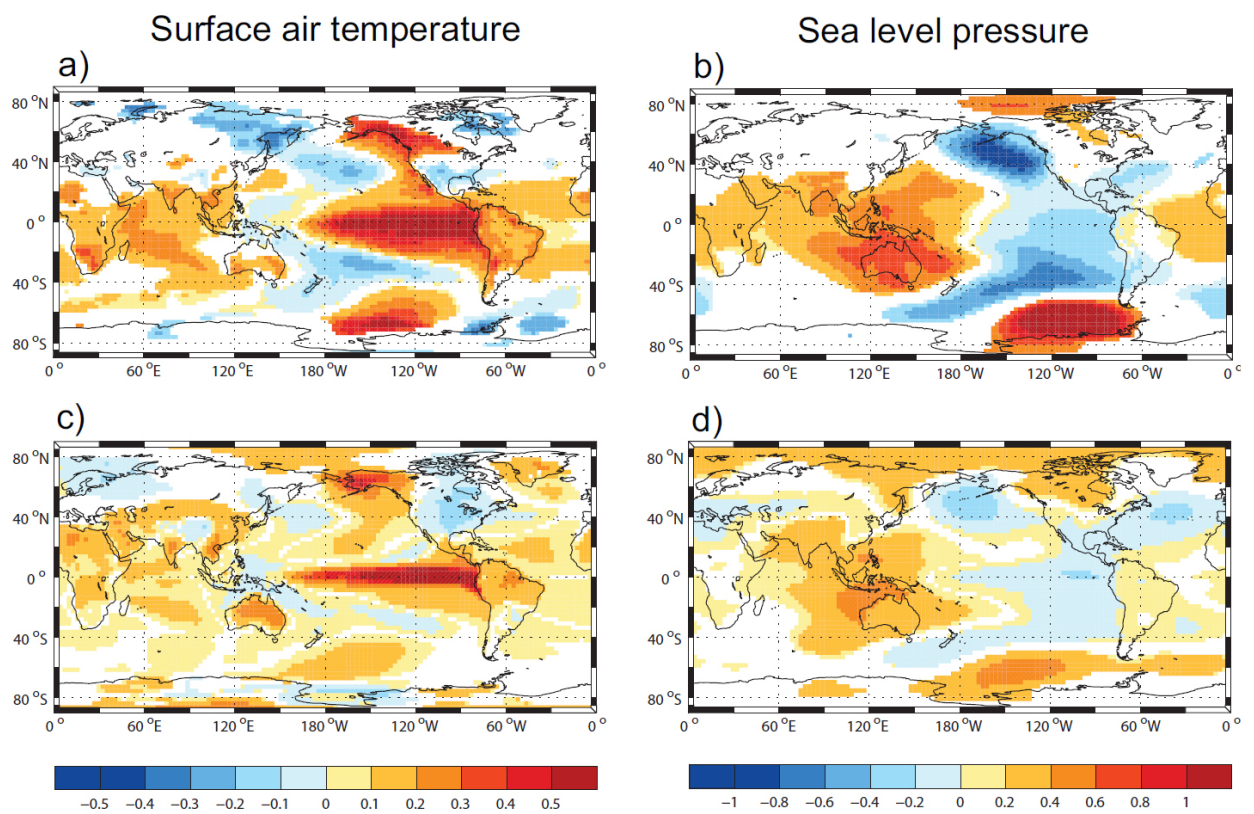

Fig. 14. Spatial pattern of anomalies in monthly mean global $2 \mathrm{~m}$ SAT (K; left panels) and SLP (hPa; right panels) associated with one standard deviation of the Niño3 index for (a-b) NCEP-NCAR and (c-d) BCM2. The patterns are derived from regression against the standardized Niño3 index.

the 3-7 year band as is found in the observations (Fig. 13b). Instead, the model variability is closer to two years and is rather weak compared to the observations.

A regression of the monthly mean $\mathrm{T} 2 \mathrm{~m}$ fields on the standardized Niño3-index suggests that the geographic signature of ENSO is realistically represented in BCM2 (Fig. 14a and c). However, compared to the NCEP data, the tongue of warm water along the Equator associated with El Niño episodes is too narrow and stretches too far west in the model, a common problem in models (Capotondi et al., 2006). Apart from this discrepancy the patterns found in BCM2 and NCEP are similar, but too weak. There are negative anomalies to the west, north and south of the warm tongue, while positive anomalies can be seen in the Indian Ocean, the tropical North Atlantic and the southern part of the Pacific. The regression patterns of the observed and simulated SLP fields on the standardized Niño3-index are shown in Fig. 14b and d. In the observations, the main feature of the regression pattern is a dipole structure across the Pacific, where positive pressure anomalies over the western Pacific and the Indian Ocean are associated with negative anomalies over large parts of the eastern Pacific (Fig. 14b). The simulated pattern show a similar structure as in the observations, but with weaker amplitude (Fig. 14d). The combination of a too weak ENSO and the cold tongue error along the Equator in the Pacific (Fig. 7a), means that the precipitation does not move much during El Niño events (not shown). This could potentially have an impact on teleconnection patterns. A more detailed analysis of the tropical variability in the model will be reserved for future studies.

\subsubsection{The Northern Annular Mode (NAM)}

The NAM (or Arctic Oscillation) is the leading climate variability mode on time scales from days to decades over the $\mathrm{NH}$ (Thompson and Wallace, 2000). The distributions of SLP and surface temperature anomalies associated with the NAM are shown in Fig. 15. The amplitudes in SLP and temperature, in units of hectopascals and kelvins, respectively, correspond to one standard deviation of the NAM-index. The NAM index, or AO index, is here defined as the leading principal component of SLP in boreal winter (DJF) over the domain from $20^{\circ}$ to $90^{\circ} \mathrm{N}$. The model realistically captures the NAM SLP dipole anomalies between the Arctic and the central North Atlantic (Fig. 15a). The main discrepancy between the model and the NCEP data is that the simulated negative center of action is too weak and extends too far west, and does not have the pronounced trough into Nordic Seas seen in the NCEP data (Fig. 15b). This is consistent with the storm tracks being too zonal in this area, a persistent problem for $\mathrm{BCM} 2$. It can also be noted that the simulated high pressure anomaly over the Pacific region is stronger than in the observations, a feature that might relate to the fact that more of the SLP-variance is explained by the NAM in the model (31\%) compared to the NCEP-NCAR reanalysis $(21 \%)$.

The anomalous SLP field associated with the NAM/AO, has a large impact on the SST and surface air temperature in the North Atlantic region. A regression of the T2m field onto the NAM-index shows that BCM2 gives a reasonably good representation of the observed leading mode of $\mathrm{T} 2 \mathrm{~m}$ variability (shown by the shading in Fig. 15). The geostrophic 


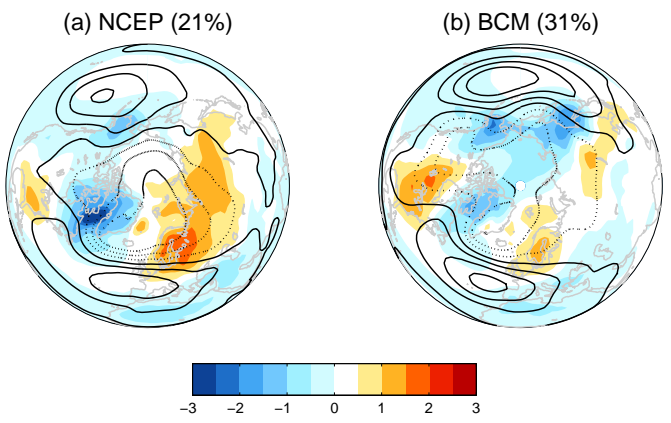

Fig. 15. Spatial pattern of anomalies in SLP (hPa; contours) and $2 \mathrm{~m}$ SAT (K; color shading) associated with one standard deviation of the AO-index. The AO-index is defined as the first principal component of winter mean SLP (December through February) for all points north of $20^{\circ} \mathrm{N}$. Both SLP and surface temperature patterns are derived from regression against the standardized AO index. (a) Spatial AO patterns for NCEP-NCAR reanalysis from 1950 through 2000, (b) similar to (a) but for years 1-600 from BCM2 PI run output. The contour interval for the SLP anomalies is $1 \mathrm{hPa}$.

winds associated with the SLP dipole anomalies induce a quadropole temperature pattern by advecting the mean temperature. This pattern is characterized by positive anomalies over southeastern North America and northern Eurasia, and negative anomalies over northeastern North America, northern Africa and through the Middle East. The main discrepancy between simulated and observed anomalies occurs near Alaska and over Siberia, with larger negative temperature anomalies than observed. This could be related to the larger SLP anomalies and the associated SLP gradients over the North Pacific in the simulation. The warming signal over northern Europe and Asia is also somewhat underestimated in the model compared to the observations, possibly related to the negative center of action being too weak over the Arctic region in the model.

\subsubsection{Southern Annular Mode (SAM)}

The SH counterpart of NAM is presented in Fig. 16. The calculation of the Southern Annular Mode [SAM, or referred to as Antarctic Oscillation (AAO)] is similar to the NAM except that monthly data for all months are used. Overall, the SAM accounts for a large part of the total variance, $32 \%$ and $30 \%$ for the NCEP-NCAR data and the BCM2, respectively. The NCEP-NCAR reanalysis and the PI simulation exhibit similar SAM patterns, with a strong zonally symmetric component, showing an out-of-phase relationship of SLP between the Antarctic and mid-latitudes at all longitudes. However, some discrepancies in the spatial structure and amplitudes of SLP and surface temperature associated with the SAM can be seen. For the SLP, the strength of the low pressure anomalies over Antarctica agrees reasonably well in terms of amplitude, but with weaker gradients. As a result of this

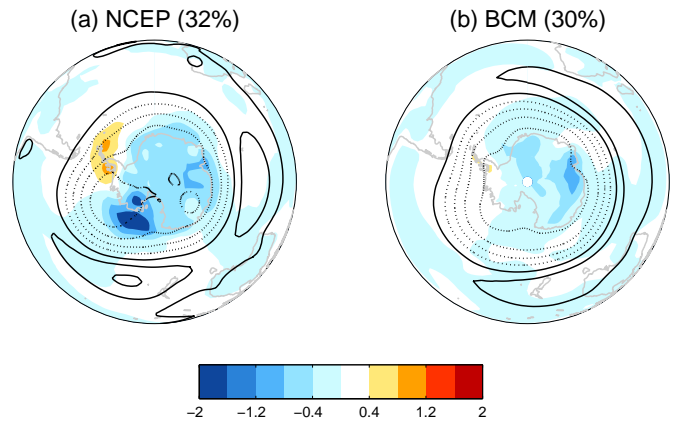

Fig. 16. Same as in Fig. 16, but for the AAO-index. The AAO index is defined as the first principal component of monthly SLP for all points south of $20^{\circ} \mathrm{S}$. (a) same as in Fig. 15a, but for AAO. (b) same as Fig. 15b, but for years 501-600 from BCM2 PI run output.

the associated winds are weaker and shifted somewhat northwards compared to the NCEP data. Also, the distinct positive anomalies in the eastern and western parts of the Pacific are not clearly visible in BCM2. A simulated cooling over the western part of Antarctica associated with SAM is in reasonable agreement with the NCEP data. However, neither the clear warming near the Weddell Sea nor the strong cooling signal over the Ross Sea are captured by the model. Many of these discrepancies are likely related to the poor sea-ice simulation in the Southern Ocean (see above), an issue that is an important part of the ongoing model development.

\section{Discussion and outlook}

In this paper, the formulation and simulation characteristics of BCM2 have been presented. The current model does not employ flux adjustments, unlike the first version of the model. A multi-century simulation for pre-industrial times has been completed, and the simulated climate is stable and reproduces many features of the observed climate quite well. In particular, the introduction of a more adequate turbulence scheme in the very stable cases (i.e. large Richardson numbers) has eliminated a persistent cold bias in the model. Furthermore, the introduction of incremental remapping for the advection of tracers in the ocean has improved the conservative properties of temperature and salt in the model, and thus reduced the drift significantly compared to earlier versions. By setting the reference pressure in the ocean at $2000 \mathrm{~m}$ and introducing a more accurate representation of density in the pressure gradient formulation, the simulated Atlantic overturning circulation appears more realistic with a shallower overturning cell compared to the first version of the model. Furthermore, the volume transports through some key sections in the model compare quite well with observed estimates, which yields further credibility to the model system. 
However, several aspects of the climate system are not very well simulated and need further attention in the future. For instance, there is a strong bias towards higher than observed SLP at the high northern latitudes, a feature that is shared by other climate models as well (Delworth et al., 2006). In addition, SLP gradients in the northern North Atlantic is too zonal, leading to too few storms entering the Nordic Seas region.

In the Southern Ocean, excessive mixing between the surface and the deep ocean lead to a strong warm bias and underestimation of sea ice extent in this region. The excessive mixing erodes the halocline and makes it difficult to maintain a fresh and cold surface layer required for wintertime freezing of sea-ice. The warm bias in the Southern Ocean will likely lead to less oceanic heat and tracer uptake in future climate change simulations than would otherwise be the case. This would lead to a larger transient climate response due to less heat going into the ocean. If used as and Earth System Model (i.e. including the full carbon cycle) such an error would also lead to a larger amount of carbon staying in the model atmosphere. Recently, oceanic and terrestrial carbon cycle models have been coupled to BCM2 to form the Bergen Earth System Model (BCM-C). An assessment of regional climate-carbon cycle feedbacks using this model system is given in Tjiputra et al. (2009).

The poor sea-ice simulation in the SH is a serious problem with the model system presented here, and will certainly be a key area for future model development. The problem with the sea-ice also makes the PI simulation less suitable for use in climate change simulations for the SH. However, it should still be applicable for climate change studies focusing on the $\mathrm{NH}$, as the climate here is generally well reproduced. It should be noted, however, that the diagnosed biases not entirely may originate from model deficiencies. As the PI simulation employs pre-industrial forcing, a comparison with NCEP data, which contain a growing anthropogenic forcing, may reveal errors which also stems from differences in external forcing between the two data sets.

Additional analyses of the simulation presented here are in progress. In particular, analyses of the multidecadal variability of the thermohaline circulation in the PI simulation and its possible link to Atlantic Multidecadal Oscillation are underway. Furthermore, model simulations for key periods in the past, such as the Last Glacial Maximum (21 ka) and the mid-Holocene $(6 \mathrm{ka})$, are planned. Such simulations will allow us to carry out detailed model-observation comparisons for the North Atlantic region during these times, both from a marine and terrestrial perspective. This will be important for furthering evaluating the realism of the model.

Finally, this simulation is the basis for a transient climate simulation of the last 600 years where most relevant forcings (natural and anthropogenic) have been incorporated. Results from these simulations will be presented in future papers. The comparisons among model results and between model and paleo data will help to better quantify the many different feedbacks from ocean, sea-ice and vegetation, and to test the climate sensitivity of the climate model. This is important not only to understand past climate variability, but even more so to increase our confidence in the models used to provide projections of future climate.

Acknowledgements. We thank C. Li and M. Deque for helpful discussions, and two anonymous reviewers for valuable comments that helped improve the manuscript. This study has been supported by the Research Council of Norway through a postdoctoral grant to O. H. O. (Project 155957), by the NorKlima project GLOMIX (Project 178399), and by the Program of Supercomputing. This is contribution No. A252 from the Bjerknes Centre for Climate Research.

Edited by: P. Jöckel

\section{References}

Assmann, K. M., Bentsen, M., Segschneider, J., and Heinze, C.: An isopycnic ocean carbon cycle model, Geosci. Model Dev. Discuss., 2, 1023-1079, 2009.

Bentsen, M., Drange, H., Furevik, T., and Zhou, T.: Simulated variability of the Atlantic Meridional Overturning Circulation, Clim. Dynam., 22, 701-720, 2004.

Bethke, I., Furevik, T., and Drange, H.: Towards a more saline North Atlantic and a fresher Arctic under global warming, Geophys. Res. Lett., 33, L21712, doi:10.1029/2006GL027264, 2006.

Bleck, R. and Smith, L. T.: A wind-driven isopycnic coordinate model of the North and Equatorial Atlantic Ocean. 1. Model development and supporting experiments, J. Geophys. Res., 95, 3273-3285, 1990.

Bleck, R., Rooth, C., Hu, D., and Smith, L. T.: Salinity-driven Thermocline Transients in a Wind- and Thermohaline-forced Isopycnic Coordinate Model of the North Atlantic, J. Phys. Oceanogr., 22, 1486-1505, 1992.

Blindheim, J.: Cascading of Barents Sea bottom water into the Norwegian Sea, Rapports et Proces-Verbaux des Reunions, Conseil International pour l'Exploration de la Mer, 188, 49-58, 1989.

Bossuet, C., Déqué, M., and Cariolle, D.: Impact of a simple parameterization of convective gravity-wave drag in a stratospheretroposphere general circulation model and its sensitivity to vertical resolution, Ann. Geophys., 16, 238-249, 1998, http://www.ann-geophys.net/16/238/1998/.

Boucher, O. and Pham, M.: History of sulfate aerosol radiative forcings, Geophys. Res. Lett., 29(9), 1308, doi:10.1029/2001GL014048, 2002.

Capotondi, A., Wittenberg, A., and Masina, S.: Spatial and temporal structure of tropical Pacific interannual variability in 20th century coupled simulations, Ocean Model., 15, 274-298, 2006.

Catry, B., Geleyn, J.-F., Bouyssel, F., Cedilnik, J., Brožková, R., Derková, M., and Mládek, R.: A new sub-grid scale lift formulation in a mountain drag parameterisation scheme, Meteorol. Z., 17, 193-208, 2008.

Cavalieri, D. J., Parkinson, C. L., and Vinnikov, K. Y.: 30year satellite record reveals contrasting Arctic and Antarctic decadal variability, Geophys. Res. Lett., 30, 1970, doi:10.1029/2003GL018031, 2003. 
de Boyer Montégut, C., Madec, G., Fischer, A. S., and Iudicone, D.: Mixed layer depth over the global ocean: An examination of profile data and a profile-based climatology, J. Geophys. Res., 109, C12003, doi:10.1029/2004JC002378, 2004.

de Szoeke, R. A.: Equation of motion using thermodynamic coordinates, J. Phys. Oceanogr., 29, 2719-2729, 2000.

Delworth, T. L., Broccoli, A., Rosati, A., Stouffer, R. J., Balaji, V., Beesley, J. A., Cooke, W. F., Dixon, K. W., Dunne, J., Dunne, K. A., Durachta, J. W., Findell, K. L., Ginoux, P., Gnanadesikan, A., Gordon, C. T., Griffies, S. M., Gudgel, R., Harrison, M. J., Held, I. M., Hemler, R. S., Horowitz, L. W., Klein, S. A., Knutson, T. R., Kushner, P. J., Langenhorst, A. R., Lee, H.-C., Lin, S.-J., Lu, J., Malyshev, S. L., Milly, P. C. D., Ramaswamy, V., Russell, J., Schwarzkopf, M. D., Shevliakova, E., Sirutis, J. J., Spelman, M. J., Stern, W. F., Winton, M., Wittenberg, A. T., Wyman, B., Zeng, F., and Zhang, R.: GFDL's CM2 global coupled climate models. Part I: Formulation and simulation characteristics, J. Climate, 19, 643-674, 2006.

Déqué, M., Dreveton, C., Braun, A., and Cariolle, D.: The ARPEGE/IFS atmosphere model: A contribution to the French community climate modelling, Clim. Dynam., 10, 249-266, 1994.

Dickson, R., Rudels, B., Dye, S., Karcher, M., Meincke, J., and Yashayaev, I.: Current estimates of freshwater flux through Arctic and subarctic seas, Prog. Oceanogr., 73, 210-230, 2007.

Douville, H., Royer, J. F., and Mahfouf, J. F.: A new snow parameterization for the Météo-France climate model. Part II: Validation in a 3D GCM experiment, Clim. Dynam., 12, 37-52, 1995.

Drange, H. and Simonsen, K.: Formulation and spin-up of the ESOP2 version of MICOM, Nansen Environmantal and Remote Sensing Center, Bergen, Norway, Tech. Rep. 117, 1996.

Duffy, P. B. and Caldeira, K. G.: Sensitivity of simulated salinities in a three-dimensional ocean general circulation model to destabilizing surface fluxes, Clim. Dynam., 15, 81-88, 1999.

Dukowicz, J. K. and Baumgardner, J. R.: Incremental remapping as a transport/advection algorithm, J. Comput. Phys., 160, 318-335, 2000.

Furevik, T., Bentsen, M., Drange, H., Kindem, I. K. T., Kvamst $\varnothing$, N. G., and Sorteberg, A.: Description and validation of the Bergen Climate Model: ARPEGE coupled with MICOM, Clim. Dynam., 21, 27-51, 2003.

Ganachaud, A. and Wunsch, C.: Improved estimates of global ocean circulation, heat transport and mixing from hydrographic data, Nature, 408, 453-457, 2000.

Gaspar, P.: Modelling the seasonal cycle of the upper ocean, J. Phys. Oceanogr., 18, 161-180, 1988.

Geleyn, J.-F.: Interpolation of wind, temperature and humidity values from model levels to the height of measurement, Tellus A, 40, 347-351, 1988.

Hallberg, R.: A themobaric instability of Lagrangial vertical coordinate ocean models, Ocean Model., 8, 279-300, 2005.

Hansen, B. and Østerhus, S.: North Atlantic - Nordic Seas exchanges, Prog. Oceanogr., 45, 109-208, 2000.

Harder, M.: Dynamik, Rauhigkeit und Alter des Meereises in der Arktis, Ph.D. thesis, Alfred-Wegner-Institut für Polar- und Meeresforschung, Bremerhaven, Germany, 1996.

Hibler, W. D.: A dynamic thermodynamic sea ice model, J. Phys. Oceanogr., 9, 815-846, 1979.
Hsu, Y. J. and Arakawa, A.: Numerical modeling of the atmosphere with an isentropic vertical coordinate, Mon. Weather Rev., 118, 1933-1959, 1990.

Hunke, E. C. and Dukowicz, J. K.: An elastic-viscous-plastic model for sea ice dynamics, J. Phys. Oceanogr., 27, 1849-1867, 1997.

Ingvaldsen, R., Loeng, H., and Asplin, L.: Variability in the Atlantic inflow to the Barents Sea based on a one-year time series from moored current meters, Cont. Shelf Res., 22, 505-519, 2002.

Janic, Z. I.: Pressure gradient force and advection schme used for forecasting with steep and smale scale topography, Beitr. Phys. Atmos., 50, 186-199, 1977.

Kalnay, E., Kanamitsu, M., Kistler, R., Collins, W., Deaven, D., Gandin, L., Iredell, M., Saha, S., White, G., Woolen, J., Zhu, Y., Chelliah, M., Ebisuzaki, W., Higgins, W., Janowiak, J., Mo, K., Ropelewski, C., Wang, J., Leetma, A., Reynolds, R., Jenne, R., and Joseph, D.: The NCEP/NCAR 40-year reanalysis project, B. Amer. Meteorol. Soc., 77(3), 437-471, 1996.

Legates, D. R. and Willmott, C. J.: Mean seasonal and spatial variability in gauge-corrected, global precipitation, Int. J. Climatol., 10, 111-127, 1990.

Levitus, S. and Boyer, T. P.: World Ocean Atlas 1994, Volume 4: Temperature, NOAA Atlas NESDIS 4, Washington, DC, 117 pp., 1994.

Levitus, S., Burgett, R., and Boyer, T. P.: World Ocean Atlas 1994, Volume 3: Salinity, NOAA Atlas NESDIS 3, Washington, DC, 99 pp., 1994.

Limpasuvan, V. and Hartmann, D. L.: Eddies and the annular modes of climate variability, Geophys. Res. Lett., 26, 3133-3136, 1999.

Loeng, H., Ozhigin, V., and Aadlandsvik, B.: Water fluxes through the Barents Sea, ICES J. Mar. Sci., 54, 310-317, 1997.

Lott, F.: Alleviation of Stationary Biases in a GCM through a Mountain Drag Parameterization Scheme and a Simple Representation of Mountain Lift Forces, Mon. Weather Rev., 125, 788 801, 1999.

Lott, F. and Miller, M. J.: A new subgrid-scale orographic drag parameterization: Its formulation and testing, Q. J. Roy. Meteor. Soc., 123, 101-127, 1997.

Louis, J.: A parametric model of vertical eddy fluxes in the atmosphere, Bound.-Lay. Meteorol., 17, 187-202, 1979.

Louis, J., Tiedtke, M., and Geleyn, J.-F.: A short history of the operational PBL parameterization at ECMWF, in: Proceedings of ECMWF workshop on planetary boundary layer parameterization, November 1981, 59-80, ECMWF, Reading, England, 1982.

Lumpkin, R. and Speer, K.: Large-scale vertical and horizontal circulation in the North Atlantic Ocean, J. Phys. Oceanogr., 33, 1902-1920, 2003.

McDougall, T. J. and Dewar, W. K.: Vertical mixing and cabbeling in layered models, J. Phys. Oceanogr., 28, 1458-1480, 1998.

McDougall, T. J. and Jackett, D. R.: An assessment of orthobaric density in the global ocean, J. Phys. Oceanogr., 35, 2054-2075, 2005.

Meehl, G. A., Stocker, T. F., Collins, W., Friedlingstein, P., Gaye, A., Gregory, J., Knutti, R., Murphy, J., Noda, A., Raper, S., Watterson, I., Weaver, A., and Zhao, Z.: Global Climate Projections, in: Climate Change 2007: The Physical Science Basis, Contribution of Working Group I to the Fourth Assessment Report of the Intergovernmental Panel on Climate Change, Cambridge University Press, Cambridge, United Kingdom and New York, NY, USA, 2007. 
Mignot, J. and Frankignoul, C.: Interannual to interdecadal variations of sea surface salinity in the Atlantic and its link to the atmosphere in a coupled model, J. Geophys. Res., 109, C04005, doi:10.1029/2003JC002005, 2004.

Oberhuber, J. M.: Simulation of the Atlantic Circulation with a Coupled Sea Ice-Mixed Layer-Isopycnal General Circulation Model. Part I: Model Description, J. Phys. Oceanogr., 23, 808$829,1993$.

Otterå, O. H.: Simulating the effects of the 1991 Mount Pinatubo volcanic eruption using the ARPEGE Atmosphere General Circulation Model, Adv. Atmos. Sci., 25, 213-226, 2008.

Otterå, O. H., Drange, H., Bentsen, M., Kvamst $\varnothing$, N. G., and Jiang, D.: The sensitivity of the present day Atlantic meridional overturning circulation to freshwater forcing, Geophys. Res. Lett., 30, 1898, doi:101029/2003GL017578, 2003.

Otterå, O. H., Drange, H., Bentsen, M., Kvamst $\varnothing$, N. G., and Jiang, D.: Transient response of the Atlantic Merdional Overturning Circulation to enhanced freshwater input to the Nordic SeasArctic Ocean in the Bergen Climate Model, Tellus A, 56, 342361, 2004.

Prather, M. J.: Numerical advection by conservation of secondorder moments, J. Geophys. Res., 91(D6), 6671-6681, 1986.

Russell, J., Stouffer, R. J., and Dixon, K. W.: Intercomparison of the Southern Ocean circulations in IPCC coupled model control simulations, J. Climate, 19, 4560-4575, 2006.

Salas-Melia, D.: A global coupled sea ice-ocean model, Ocean Model., 4, 137-172, 2002.

Schauer, U., Loeng, H., Rudels, B., Ozhigin, V. K., and Dieck, W.: Atlantic Water flow through the Barents and Kara Seas, Deep Sea Res., 49, 2281-2298, 2002.

Schmittner, A., Latif, M., and Schneider, B.: Model projections of the North Atlantic thermohaline circulation for the 21st century assessed by observation, Geophys. Res. Lett., 32, L23710, doi:10.1029/2005GL024368, 2005.

Sorteberg, A., Furevik, T., Drange, H., and Kvamst, N. G.: Effects of simulated natural variability on Arctic temperature projections, Geophys. Res. Lett., 32, L18708, doi:10.1029/2005GL023404, 2005.

Spencer, R. W.: Global oceanic precipitation from the MSU during 1979-91 and comparisons to other climatologies, J. Climate, 6, 1301-1326, 1993.

Steele, M., Morley, R., and Ermold, W.: PHC: A global ocean hydrography with high-quality Arctic Ocean, J. Climate, 14, 2079 2087, 2001.
Stouffer, R. J., Weaver, A. J., and Eby, M.: A method for obtaining pre-twentieth century initial conditions for use in climate change studies, Clim. Dynam., 23, 327-339, 2004.

Sun, S. and Bleck, R.: Multi-century simulations with the coupled GISSHYCOM climate model: control experiments, Clim. Dynam., 26, 407-428, 2006.

Sun, S., Bleck, R., Rooth, C., Dukowicz, J., Chassignet, E., and Kilworth, P.: Inclusion of Thermobaricity in Isopycnic-Coordinate Ocean Models, J. Phys. Oceanogr., 29, 2719-2729, 1999.

Tanre, D., Geleyn, J.-F., and Slingo, J. M.: First results of the introduction of an advanced aerosol-radiation interaction in the ECMWF low resolution global model, in: Aerosols and Their Climatic Effects, edited by: Gerber, H. E. and Deepak, A., A. Deepak Publ., Hampton, Virginia, USA, 133-177, 1984.

Terray, L. and Thual, O.: Oasis: le couplage océan-atmosphére, La Météorologie, 10, 50-61, 1995.

Terray, L., Thual, O., Belamari, S., Déqué, M., Dandin, P., Lévy, C., and Delecluse, P.: Climatology and interannual variability simulated by the arpege-opa model, Clim. Dynam., 11, 487-505, 1995.

Thompson, D. W. J. and Wallace, J. M.: Annular modes in the extratropical circulation, part I, Month-to-month variability, J. Climate, 13, 1000-1016, 2000.

Thorndike, A. S., Rothrock, D. A., Maykut, G. A., and Colony, R.: The thikness distribution of sea ice, J. Geophys. Res., 80, 45014513, 1975.

Tjiputra, J. F., Assmann, K., Bentsen, M., Bethke, I., Otterå, O. H., Sturm, C., and Heinze, C.: Bergen earth system model (BCM-C): model description and regional climate-carbon cycle feedbacks assessment, Geosci. Model Dev. Discuss., 2, 845-887, 2009.

Trenberth, K. E. and Caron, J. M.: Estimates of meridional atmosphere and ocean transports, J. Climate, 14, 3433-3443, 2001.

Wijffels, S. E., Mayers, G., and Godfrey, J. S.: A 20-yr average of the Indonesian Throughflow: Regional currents and the interbasin exchange, J. Phys. Oceanogr., 38, 1965-1978, 2008.

Withworth, T. and Peterson, R.: Volume transport of the Antarctic Circumpolar Current from bottom water measurements, J. Phys. Oceanogr., 15, 810-816, 1985.

Yu, L., Gao, Y., Wang, H., and Drange, H.: Revisiting the effect of ocean diapycnal mixing on the Atlantic Merdional Overturning Circulation recovery in a freshwater perturbation experiment, Adv. Atmos. Sci., 25, 597-609, 2008. 